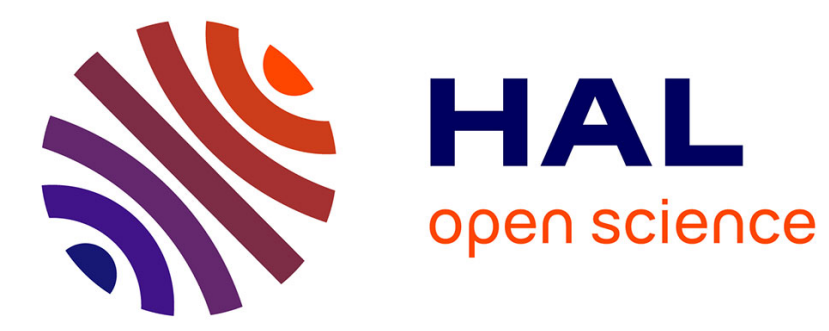

\title{
Modeling for effective collaboration in telemedicine
}

Bernard Kamsu-Foguem, Pierre Tiako, Laure Fotso, Clovis Foguem

\section{To cite this version:}

Bernard Kamsu-Foguem, Pierre Tiako, Laure Fotso, Clovis Foguem. Modeling for effective collaboration in telemedicine. Telematics and Informatics, 2015, vol. 32 (4), pp. 776-786. 10.1016/j.tele.2015.03.009 . hal-01154601

\section{HAL Id: hal-01154601 \\ https://hal.science/hal-01154601}

Submitted on 15 Jun 2015

HAL is a multi-disciplinary open access archive for the deposit and dissemination of scientific research documents, whether they are published or not. The documents may come from teaching and research institutions in France or abroad, or from public or private research centers.
L'archive ouverte pluridisciplinaire HAL, est destinée au dépôt et à la diffusion de documents scientifiques de niveau recherche, publiés ou non, émanant des établissements d'enseignement et de recherche français ou étrangers, des laboratoires publics ou privés. 


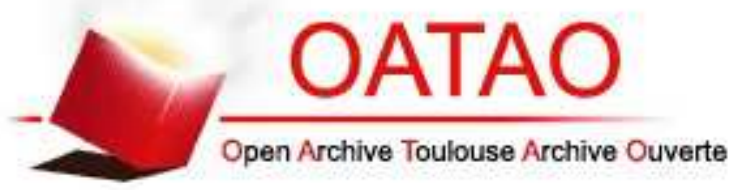

\section{Open Archive Toulouse Archive Ouverte (OATAO)}

OATAO is an open access repository that collects the work of Toulouse researchers and makes it freely available over the web where possible.

This is an author-deposited version published in: http://oatao.univ-toulouse.fr/ Eprints ID: 13833

To link to this article: DOI:10.1016/j.tele.2015.03.009

http://dx.doi.org/10.1016/j.tele.2015.03.009

\section{To cite this version:}

Kamsu-Foguem, Bernard and Tiako, Pierre and Fotso, Laure and Foguem, Clovis Modeling for effective collaboration in telemedicine. (2015) Telematics and Informatics, vol. 32. pp. 776-786. ISSN 0736-5853 


\title{
Modeling for effective collaboration in telemedicine
}

\author{
Bernard Kamsu-Foguem ${ }^{\mathrm{a}, *}$, Pierre F. Tiako ${ }^{\mathrm{b}, \mathrm{c}}$, Laure P. Fotso $^{\mathrm{d}}$, Clovis Foguem ${ }^{\mathrm{e}, \mathrm{f}}$ \\ a Laboratory of Production Engineering (LGP), EA 1905, ENIT-INPT University of Toulouse, 47 Avenue d'Azereix, BP 1629, 65016, Tarbes Cedex, France \\ ${ }^{\mathrm{b}}$ Center for IT Research, Langston University, OK 73050, USA \\ 'Center for IT RED, Tiako University, OK 73106, USA \\ 'Département d'Informatique, Faculté des Sciences, Université de Yaoundé I, B.P. 812, Yaoundé, Cameroon

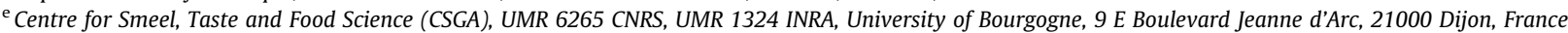 \\ ${ }_{\mathrm{f}}^{\mathrm{f}}$ Auban Moët Hospital, 51200 Epernay, France
}

Keywords:

Telemedicine

Information

Requirements

Knowledge

Collaboration

Modeling

\begin{abstract}
A B S T R A C T
Telemedicine is a remote medical practice, which utilizes advanced telecommunications and information technologies for the delivery of healthcare and the exchange of heath information across distances. The development of telemedicine has significantly changed the medical collaborative decision making and doctor-patient relationships and has an impact on the responsibilities of physicians to patients and how to treat them. Moreover, in the chain of medical care information exchanged between a requesting physician and medical expert should assist in decision making. In this regard, we propose means for the formalization of exchanges, which is very important because it facilitates a transparent and traceable understanding of the remote process. So, we engage knowledge-based modeling for supporting collaborative activities in telemedicine. This includes the engagement of formal ontologies to ensure structuration of terminology and identification across all entities in a domain so that multiple sources of data can be aggregated through comparable reference terms. The provided benefit is the generated support for logic-based intelligent applications that are able to perform complex reasoning tasks such as checking for errors and inconsistencies and deriving logical inferences.
\end{abstract}

\section{Introduction}

The European Union (EU) and its European Commission (EC) have implemented policies, models with conceptual and technical guidelines for supporting and encouraging research projects related to telemedicine. In addition, the draft directive on patients' rights in cross-border healthcare advocates cooperation in health including the establishment of referral networks, evaluation of medical technologies, data collection, quality, and safety (Saliba et al., 2012). These projects include the creation of a network of Community Technology Assessment health centers to promote collaboration between national health authorities and the provision of timely, objective, reliable, transparent, and transferable solutions. Sharing of health technologies, in the short and long term, enable effective exchange of information within the network and support the decision making by EU Member States related to the effectiveness and sustainability of actions related to improving and controlling quality patient care. This objective has been implemented successfully in recent years with cross-border teleneuromonitoring collaboration between hospitals in the Netherlands, Germany, and Switzerland (Doering et al., 2013).

\footnotetext{
* Corresponding author. Tel.: +336243023 37; fax: +33 562442708.

E-mail address: Bernard.Kamsu-Foguem@enit.fr (B. Kamsu-Foguem).
} 
Especially with a view to the widespread deployment of telemedicine services in Europe, it is necessary to rely as much as possible on standards, infrastructure, and exchange formats. The European Community organizes the implementation of interoperability standards on three levels:

- High-level: national or regional projects (e.g., the interoperability framework of ASIP Santé-the shared healthcare information systems agency, European projects such epSOS, adapted to the French context).

- Intermediate level: integration Profiles to address key issues (e.g., IHE, Continua Health Alliance).

- Low level: standards (e.g., HL7, DICOM, IEEE, W3C, Oasis, etc) and interfaces between systems.

The aims of this study include ensuring the structuring of exchanges (e.g., clinical data associated with the request for an opinion, formalizing the response of the expert sought by means of guidelines assuring collaboration, identification of the professionals involved), and guaranteeing security (confidentiality, integrity, traceability, centralized archiving).

The rest of the paper is structured as follows. Section 2 exposes the collaboration in telemedicine with activities and actors involved and types of exchanged data and challenges for data sharing in telemedicine. Section 3 presents requirements and modeling for collaboration in Telemedicine through ontology modeling for semantic specification and knowledge capitalisation from remote collaborative expertise for the effective deployment of telemedicine. Finally, Sections 4 and 5 conclude and discuss lessons learned and future challenges.

\section{Collaboration in telemedicine practices: state and necessities}

\subsection{Activities and actors involved}

Telemedicine is a remote medical practice, which utilizes advanced telecommunications and information technologies for the delivery of healthcare and the exchange of heath information across distances, including the following medical activities (see Fig. 1) (Simon and Pellitteri, 2012):

- Tele-consultation, a procedure whereby medical professionals can consult a patient remotely and interpret the necessary data remotely for medical follow-up;

- Tele-expertise, whereby a medical professional can seek remotely an opinion of other medical professionals who have the relevant training or skills;

- Tele-monitoring, the ability to monitor and supervise patients remotely;

- Tele-assistance, a procedure, which enables a medical professional to assist remotely another healthcare professional during the realization of a medical act.

Telemedicine is becoming an integrated tool in the delivery of health care and will soon be a part of mainstream medicine, but the practice of telemedicine is difficult and complex. Telemedicine assists collaborating medical professionals with shared decision-making in medical diagnosis and treatment. Referring (requesting) physicians should involve patients in the decision to seek further medical actions involving the choice of a specialist/consultant, as a starting point for more in-depth investigations into underlying causes. The procedure allows the specialist to investigate more thoroughly the compatibility

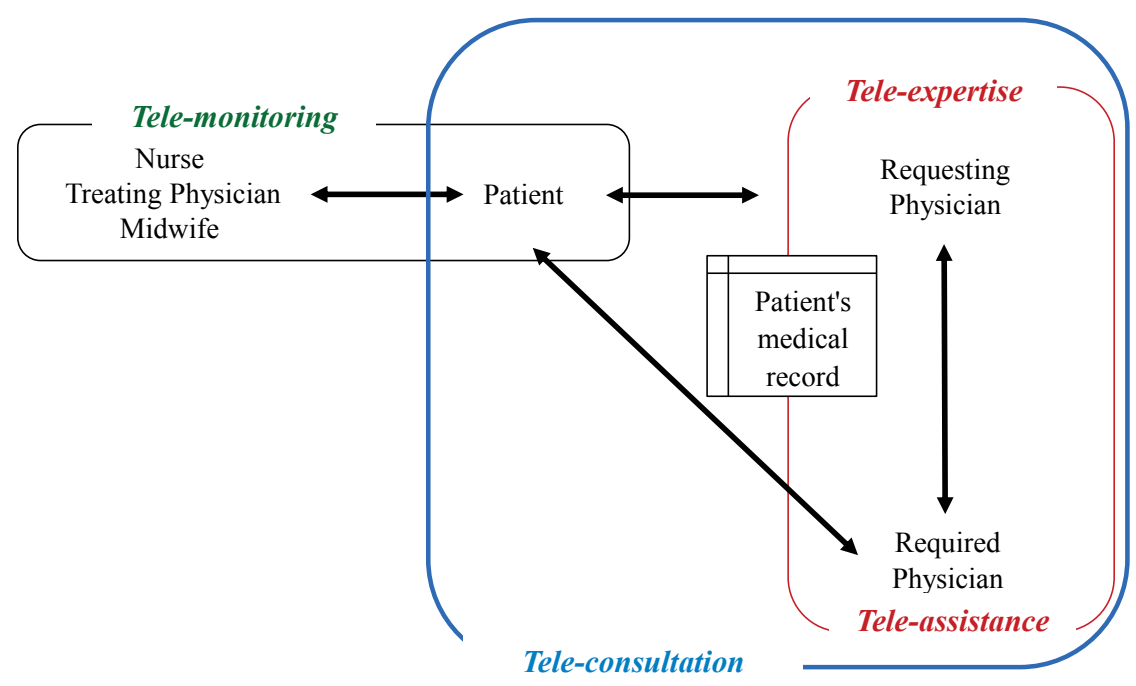

Fig. 1. Typology of telemedicine activities. 
of the medical scheme with the specific situation and to pursue discussions with the referring (requesting) physicians about the proposed management plan including supposed diagnosis and corresponding treatments. The requesting physician must distinguish groups of patients with similar symptoms (e.g., fever, abdominal pain) and benign disease, from those with more serious health issues who require immediate treatment. It is the duty of the requesting physician to provide the patient with the information necessary for a free and informed consent. For their part, the consulting (required) physician must ensure that he/she has a in hand all the necessary information since the consulting physician is responsible for the diagnosis and treatment formula recommended.

In many cases, the final diagnosis will be made only secondarily on the basis of a clinical evaluation or the result of further examination, while the prognosis of patients with the most serious disorders may be evident early on. Physicians have the choice either minimizing or maximizing diagnostic procedures (e.g., biology, imaging), providing treatment (e.g., antibiotics, hospitalization, monitoring) or some mixed procedure (e.g., diagnostic or therapeutic laparotomy). A strategy of minimizing procedures reduces the invasiveness of care, risks (e.g., resistant bacteria, nosocomial infections, adverse drug reactions, and the vagaries of interventions) and their costs, but with a hazard of diagnostic and therapeutic delays whose ethical and medico-legal consequences can be cumbersome. In contrast, a strategy for maximizing procedures reduces the risk of missing a severe condition in its early stages (e.g., a disseminated bacterial infection, appendicitis, or appendicular peritonitis); thus, also reducing the individual and collective risks, as well as, costs as described above. Medical decisions are the result of some functions of logistical, ethical, legal, and security constraints and these processes may be conscious or subconscious. To inform the medical decision making process, the clinician may rely on the opinion of other doctors. When it is formalized in a clear set of rules that are conveyed to and understood by medical staff, this opinion may take the form of a clinical protocol of care, practice guidelines, or consensus conferences. These forms of decision aids are based on expert opinion and analysis of the literature in a more or less structured way. Telemedicine is a new kind of decision aid that has experienced sustained development and confirmed its capacity to combine that progress with high quality.

Collaboration is needed among physicians or between physicians and other healthcare professionals involved in telemedicine protocols in accordance with the areas of different and complementary skills so that everyone is responsible for his/her actions and decisions. Several models of tele-consultation are possible depending on the nature of the teleconsultation and location, whether the medical service is public or private, and where services are consumed and where they are realized. When responsibilities are involved we distinguish: tele-consultation among public health care (PHC) institutions, where the patient is a user and medical officers in the public service; tele-consultation performed among health facilities (HF) where the patient has a private contractual relationship with the requesting physician and the physician required; and tele-consultation between PHC institutions, where the patient is hospitalized and a physician who is practicing in a private facility.

In the organization of care, PHC hospitals are responsible for adoption and usage of telemedicine made by doctors. Cooperation among the PHC is a public policy function comprising public service requirements and a social function, involving innovative, cost-effective and diversified organization models. Insofar as the public service mission covers new services, there is, in principle, the same requirement of adaptability to the best technologies and the best care. There is no need to conclude a cooperative agreement among public hospital units and networks to develop telemedicine if it provides better care. It is, therefore, the responsibility of the public practitioner to share their skills with their peers. Telemedicine is a practical tool that allows practitioners to pool their resources, share expertise, exchange ideas, and undertake joint action. However, in every case, for the collaboration provided for by telemedicine to apply, the public service mission needs to be clearly defined and must be explicitly entrusted through an act of public authority (including contracts or cooperative agreements).

\subsection{Type of data exchanged and challenges for data sharing in telemedicine}

Telemedicine applications, which are used to establish a diagnosis and monitor patients for preventive and curative care, require expert advice to develop a therapeutic decision, to prescribe treatment, recommend or perform services or other acts, or monitor the patient's condition. It is in this context that telemedicine has been developed. It allows organized networks to share information and skills, improve the management of patients, both for emergency care and chronic diseases (such as, cardiovascular diseases, diabetes mellitus, respiratory diseases, chronic renal failure (CRF), cancer, nervous system disorders, musculoskeletal disease (MD) or multi-morbid patients) (van den Berg et al., 2012). The types of telemedical intervention include: measurement of vital signs using telemedical devices, interactive systems, or personal interaction between healthcare provider and patient.

Among other medical acts, telemedicine induces the same obligations for the physician, and patients benefit from the same rights as in a conventional medical practice. Non-compliance may engage professional oversight authorities.

Telemedicine aims are indispensable as the trend of the medical profession grows increasingly towards specialties and subspecialties. Now a patient visiting a general practitioner can consult a specialist via telecommunication facilities, saving both time and money for quality medical care as opposed to the method of transporting patients to specialists for face-toface visits (Ekeland et al., 2010).

Telemedicine highlights mainly two categories of equal importance (Adewale, 2004): 
- Increasing diagnostic complexity often requires peer-to-peer consultation based on data (e.g., images), i.e., tele-consultation. Both, a tele-consultation of an expert or of a knowledge based system, are conceivable.

- Telemedicine is a tool to ensure equity of healthcare for those people living in rural and remote areas having specialised needs without convenient access to medical services compared to those in urban areas as well as the aspect of home care for specific groups such as the elderly.

Several examples can illustrate the importance of clinical research in telemedicine. In type 1 diabetes, after the first inconclusive results due to insufficient or weak methodologies, the French study TeleDiab 1 brought for the first time a clinical improvement over 6 months in patients followed-up remotely by Diabeo software and tele-consultation (Franc et al., 2011). This software enables individualized insulin dose adjustments combined with telemedicine support (Charpentier et al., 2011) and the main medical service to patients was a decreased risk of complications. In the use of telemedicine for chronic heart disease, the results of two meta-analyses showed a significant $30 \%$ reduction in morbidity and mortality (Clark et al., 2007; Polisena et al., 2010) (see Tables 1 and 2).

Telemedicine opens up significant opportunities for progress in key medicine areas. The goal is to give patients access to care throughout the nation with real professional interactions among remote medical teams. Telemedicine facilitates the development of real networks where the notion of complementarity and multidisciplinarity become sources of efficiency, quality, and safety. Establishing a network of institutions and health professionals promotes the formation of care channels. Telemedicine removes barriers to collaboration to ensure a better understanding of the interaction of medical programs across country, continent, or world and as it fits into the medical organization's overall service structure. The telemedicine approach is important because health care organizations are moving away from a facility-specific perspective with paperbased records to one that focuses more on considerations relevant to the health care system as a whole with electronic records (see Fig. 2). The Personal Medical Record (PMR) is a tool for telemedicine, which stores all data, reviews, images and consultations in a secured manner.

The development of telemedicine has significantly changed the doctor-patient relationship and has an impact on the responsibility of physicians to patients and how to treat them. The legal consequences of telemedicine are manifold, indeed the responsibility of different stakeholders is difficult to determine and, in general, each physician (whether expert or applicant) must perform certain essential actions. Moreover, in the chain of medical care information exchanged between a requesting physician and medical expert should assist in decision making. In this regard, formalization of exchanges is very important because it facilitates a transparent and traceable understanding of the telemedical process. This requires the definition of a suitable data exchange format adapted to the needs of performance assessment and secure information management. Therefore, confidentiality must be respected, and protection should be guaranteed by law through ethical principles and formal rules concerning the information to be shared, the procedures for sharing it, and the security of confidential information (Chopard et al., 2012). A balance must be found between the information that the patient wishes to share and that that must be kept private. To organize the legal framework for telemedicine, structures and regulations aimed at identifying the key confidentiality requirements of all system procedures are needed (Pattynama, 2010). Mastering technology issues or providing training remain essential matters for implementation of telemedicine, but legal issues may constrain practical deployment (Siegal, 2011). Health information technology will have to define new management tools that will be required of the information society to allow the health delivery system to adapt to new fields of application, as to maintain the humanist dimension of telemedicine that favors neither excessive centralization nor sectorial specialization.

\section{Requirements and modeling for collaboration in telemedicine}

\subsection{Functional requirements for the effective deployment of telemedicine}

Basically, some needs associated with endeavoring to complete such a telemedicine activity involve functional requirements of five types (DGOS, 2012):

- general organization of the telemedicine activity,

- remote interaction and exchange (audio/video),

Table 1

Examples of information collected and shared in telemedicine.

\begin{tabular}{|c|c|c|c|}
\hline Data from medical devices & $\begin{array}{l}\text { Telemedicine activity -specific } \\
\text { clinical data }\end{array}$ & $\begin{array}{l}\text { Patient record (general } \\
\text { or specialized medicine) }\end{array}$ & Medical examination results \\
\hline $\begin{array}{l}\text { - Measurements (blood pressure, } \\
\text { blood glucose, pulse and tem- } \\
\text { perature, etc.) } \\
\text { - Physiological signals (Stetho- } \\
\text { scope, ECG, EEG, EMG, etc.) } \\
\text { - Static and dynamic imaging (e.g. } \\
\text { the multi-slice CT or the open } \\
\text { MRI system) }\end{array}$ & $\begin{array}{l}\text { - Request for an execution of a } \\
\text { telemedicine activity } \\
\text { - Report from execution of the } \\
\text { telemedicine activity } \\
\text { - Recommendations or pre- } \\
\text { scriptions issued in the tele- } \\
\text { medicine activity }\end{array}$ & $\begin{array}{l}\text { - Report of medical } \\
\text { consultation or } \\
\text { hospitalization } \\
\text { - Medication } \\
\text { prescriptions } \\
\text { - Diet and lifestyle } \\
\text { recommendations }\end{array}$ & $\begin{array}{l}\text { - Medical imaging (photo or video style) } \\
\text { - Medical signals } \\
\text { - Biological outcomes. } \\
\text { - Gross, microscopic, chemical, immuno- } \\
\text { logic and molecular examination of } \\
\text { organs and tissues }\end{array}$ \\
\hline
\end{tabular}


Table 2

The functional requirements associated with achieving an effective telemedicine (DGOS, 2012).

\begin{tabular}{|c|c|c|c|}
\hline Functionality & Component & Description & Interoperability \\
\hline \multirow[t]{2}{*}{$\begin{array}{l}\text { General organization of } \\
\text { the telemedicine } \\
\text { activity }\end{array}$} & $\begin{array}{l}\text { Workflow (a depiction of a } \\
\text { sequence of operations) and } \\
\text { planning engine }\end{array}$ & $\begin{array}{l}\text { Manages the request of the activity, planning, } \\
\text { assignment final actor, indicators of } \\
\text { achievement of the act (to do, done, } \\
\text { documented, billed) }\end{array}$ & $\begin{array}{l}\text { Produces a guide on the phased } \\
\text { implementation of the national health } \\
\text { identifier (NHI) } \\
\text { By connecting to a directory of actors } \\
\text { integrating target connection to } \\
\text { repository of social health actors } \\
\text { (RSHA) } \\
\text { Can rely on a secure messaging service }\end{array}$ \\
\hline & $\begin{array}{l}\text { Technical monitoring of the } \\
\text { activity }\end{array}$ & $\begin{array}{l}\text { Allows the actors of caretaking/maintenance } \\
\text { services to verify the operability of the device } \\
\text { and to provide technical traceability in the } \\
\text { realization of the activity }\end{array}$ & $\begin{array}{l}\text { From a syntactic point of view, a } \\
\text { service-oriented architecture is } \\
\text { encouraging } \\
\text { Semantic interoperability depends on } \\
\text { how the interfaces to a service are } \\
\text { labeled and how the meaning of the } \\
\text { information is shared }\end{array}$ \\
\hline \multirow[t]{4}{*}{$\begin{array}{l}\text { Remote interaction and } \\
\text { exchange (audio/video) }\end{array}$} & $\begin{array}{l}\text { Videoconferencing/ } \\
\text { Audioconferencing }\end{array}$ & Non-specific industrial solution to health & $\begin{array}{l}\text { Standard videoconference as a means of } \\
\text { facilitating a comprehensive set of } \\
\text { collaboration capabilities }\end{array}$ \\
\hline & Telepresence & $\begin{array}{l}\text { High-end proprietary solution deployed on } \\
\text { dedicated sites }\end{array}$ & none \\
\hline & Webconference & $\begin{array}{l}\text { Lightweight videoconferencing solution } \\
\text { between computers equipped with webcams }\end{array}$ & $\begin{array}{l}\text { Lack of interoperability, client deployed } \\
\text { "on-the-fly" }\end{array}$ \\
\hline & $\begin{array}{l}\text { Videoconferencing } \\
\text { embedded into a } \\
\text { telemedicine tool }\end{array}$ & $\begin{array}{l}\text { Functionality included as part of software } \\
\text { handling a work area of the telemedicine }\end{array}$ & $\begin{array}{l}\text { Depending on the management } \\
\text { software for work area of the } \\
\text { telemedicine }\end{array}$ \\
\hline $\begin{array}{l}\text { Temporary sharing of } \\
\text { medical data required } \\
\text { for an execution of the } \\
\text { telemedicine activity }\end{array}$ & Telemedicine tool & $\begin{array}{l}\text { Solution used in the activity by actors offering } \\
\text { package of business functionalities correlated } \\
\text { with an identified patient: } \\
\text { - Visio } \\
\text { - Viewer Digital Imaging and Communica- } \\
\text { tions in Medicine (DICOM) } \\
\text { - Application sharing with streaming or } \\
\text { with "whiteboard" function } \\
\text { - Document storage area replicated on the } \\
\text { computer of each participant }\end{array}$ & $\begin{array}{l}\text { NHI retrieval from workflow engine } \\
\text { Authentication of the health } \\
\text { professionals }\end{array}$ \\
\hline \multirow[t]{3}{*}{$\begin{array}{l}\text { Transmission of medical } \\
\text { documents useful for } \\
\text { an execution of the } \\
\text { telemedicine activity }\end{array}$} & $\begin{array}{l}\text { Communicating medical } \\
\text { devices and related software } \\
\text { useful documents for } \\
\text { coordinating cares }\end{array}$ & $\begin{array}{l}\text { Measurement sensors and physiological } \\
\text { signals, data routing and forwarding, Alert } \\
\text { Manager, providing data in a business } \\
\text { Graphical User Interface (GUI) }\end{array}$ & $\begin{array}{l}\text { Identity retrieval for injection into the } \\
\text { whole chain of medical data processing } \\
\text { The responsibility of the technical third } \\
\text { party requires the control of the entire } \\
\text { chain }\end{array}$ \\
\hline & $\begin{array}{l}\text { Picture Archiving and } \\
\text { Communication System } \\
\text { (PACS) }\end{array}$ & DICOM Storage Service & DICOM \\
\hline & $\begin{array}{l}\text { Connected biomedical } \\
\text { device }\end{array}$ & $\begin{array}{l}\text { Device capable of producing an output file } \\
\text { sent by unified messaging or secure } \\
\text { messaging }\end{array}$ & Depends on the transport service \\
\hline \multirow[t]{2}{*}{$\begin{array}{l}\text { Sharing/exchange of } \\
\text { useful documents for } \\
\text { coordinating cares }\end{array}$} & $\begin{array}{l}\text { Personal Medical Record } \\
\text { (PMR) }\end{array}$ & $\begin{array}{l}\text { Consultation of medical documents useful for } \\
\text { coordinating cares }\end{array}$ & $\begin{array}{l}\text { NHI } \\
\text { Healthcare Professional's Smartcard } \\
\text { (HPS) } \\
\text { Health information system } \\
\text { interoperability framework and PMR } \\
\text { compatibility }\end{array}$ \\
\hline & Secure messaging structure & $\begin{array}{l}\text { Document exchanges between health } \\
\text { professionals (with eventually a copy in the } \\
\text { patient PMR) }\end{array}$ & $\begin{array}{l}\text { The same interoperability requirements } \\
\text { as for PMR } \\
\text { Cross-document Messaging (XDM) } \\
\text { attachments }\end{array}$ \\
\hline
\end{tabular}

- temporary sharing of medical data required for an execution of the telemedicine activity,

- transmission of medical documents useful for an execution of the telemedicine activity,

- sharing/exchange of useful documents for coordinating cares.

For each proposed establishment of a telemedicine activity at the regional level, the macro-functional requirements should be detailed and adapted to the local environment. The provided information technology system would enable a 


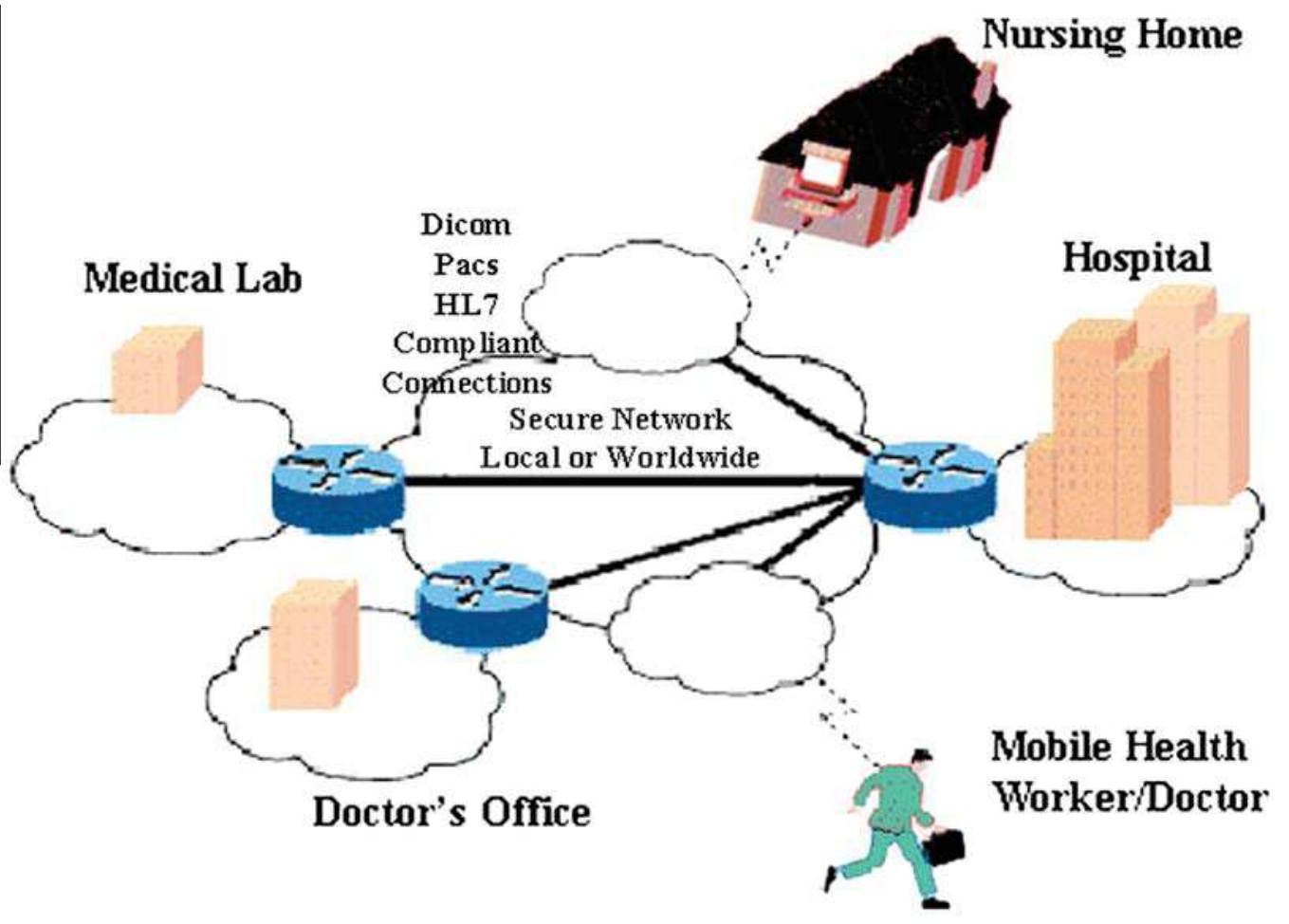

Fig. 2. Technical framework of operating in the telemedicine (Telemd, 2013).

degree of flexibility that necessary means the assessment of organizational and technical resources for the proper implementation of the collaborative work.

The deployment of information sharing can follow three implementation schemes of collaboration models (not exclusive):

- Synchronous collaboration model with strong coupling: whereby participants have their own identical perspective about one document previously distributed on each local workstation. The distributed application on each workstation provides a shared vision of this document by showing simultaneous identical presentation.

- Synchronous collaboration model with loose coupling: whereby participants use the same application (preliminary remote loading or model in which software and associated data are centrally hosted on the cloud) to access the same information and documents without coupling vision (each actor can move in the document and place the screen on a different page of the other actors involved in the activity).

- Asynchronous collaboration model can also be allowed in some situations, such as in reading radiology reports. The request for consultations, sharing of medical information and any action to be taken are asynchronous. A document (patient record, a shuttle service, etc) must trace and draw information exchanges. The exchanges of images are made in an asynchronous form, while audio and video exchanges are synchronous.

An application may propose these models to adapt to the needs of collaboration depending on the nature of the shared information. This action will have to be implemented at both regional and transnational level in order to adapt to the conditions of comprehensive interoperability and collaboration in this field. In the majority of current cases (projects in the experimental phase or still in a development phase), a large number of suppliers ensured a sufficient level of support of their equipment/software, but the operational support (first level) is provided by medical/paramedical staff, involved in collaboration with suppliers of technological and virtualization solutions.

\subsection{Ontology modeling for semantic specification}

A collaborative approach for telemedicine management will allow stakeholders to work together and lead to better decision-making processes in integrating the knowledge of each business domain.

Productive exchanges between health professionals, officials, and operators are a prerequisite for the harmonious development of this new form of medical practice. The transmission of medical data and the possibility for several distant physicians to 
share their knowledge about a given medical case raise several conceptual and technical questions. Among them there is the problem of the interoperability of the medical information. Finding solutions to interoperability is mandatory to ensure the reliability and sustainability of telemedicine. This study is focused on semantic interoperability that concerns mutual understanding of terminologies and concepts used, but also performing the intended actions comprehensively and safely.

The conceptual semantic interoperability must ensure that the information exchanged is understandable from the point of view of its meaning and its interpretation by the applications that use this information but have been developed for different purposes. The challenge consists in semantic harmonization and the use of concepts and services respecting common rules, constraints, and common conditions. In particular, semantic interoperability will involve understanding the terminologies and concepts, but also the performance of medical procedures considered most completely and efficiently as possible. The research work presented in this paper focuses on the semantic level of interoperability to allow different actors of telemedicine to share and use knowledge models representing best practices. The proposed approach is to articulate the ontologies directories with reasonable axioms and rules for modeling the semantic regulations of telemedicine. The proposed approach therefore concerns a reflection from legal constraints (Right to information and right to civil liability) caused by telemedicine and other technological properties needed to facilitate reasoning and medical decision making. To facilitate the tele-consultation, the use of digital media on the model of the remote practices with medical devices should incorporate intelligent systems designed to help physicians to find out how to support assessments of software service and deal with legal problems. Finding solutions to legal problems and technology (interoperability) is essential to ensure the reliability and sustainability of the Telemedicine. Likewise, it is indispensable to keep a humanistic dimension in order to build confidence to promote mutual respect and a fruitful dialogue among all stakeholders.

Telemedicine is also defined as the use of telecommunication technology in the provision of health care (DOC, 1997). Telemedicine is by nature a teamwork activity. Therefore, we adopted and adapted process models from team-based software engineering work (Tiako, 2011a,b) for defining the proposed telemedicine expert model of Fig. 3.

The telemedicine expert Process model proposed is composed of the following entities: Patient, Activity, Competency, Participant, Tool, and Object.

- Patient: a telemedicine process schedules a patient to be treated;

- Activity: a medical activity is rooted in a telemedicine process. It can have sub-activities and it is constrained by medical directions. An activity has objects as input and output and it needs medical competencies for performing treatments.

- Competency: represents the skill set of medical participants involved in an activity;

- Directions: procedures to be followed when performing an activity, including guidelines that govern the behavior of medical participants involved in an activity;

- Tools: used by telemedicine experts, which include computers, knowledge-based systems, digital radiography, etc. (Stamm et al., 1998) to be used by participants for accessing, forwarding, receiving, and sharing medical objects;

- Objects: as defined in telemedicine include information, documents, samples, or organs exchanged among medical participants and/or among a patient and medical participants.

Cardinality (a:b) involved between two relations of our model indicates the number of instances of an entity and the cardinality is attached to in relation to the other entity. The dark square attached to one entity indicates how to read the relation. For instance, cardinality $(1, n)$ attached to entity Activity in relation with entity Competency indicates that each telemedicine activity will need at least one medical expert to be involved. Cardinality shows the patient feeding into the model but not the process, which then provides feedback through the participant to the patient.

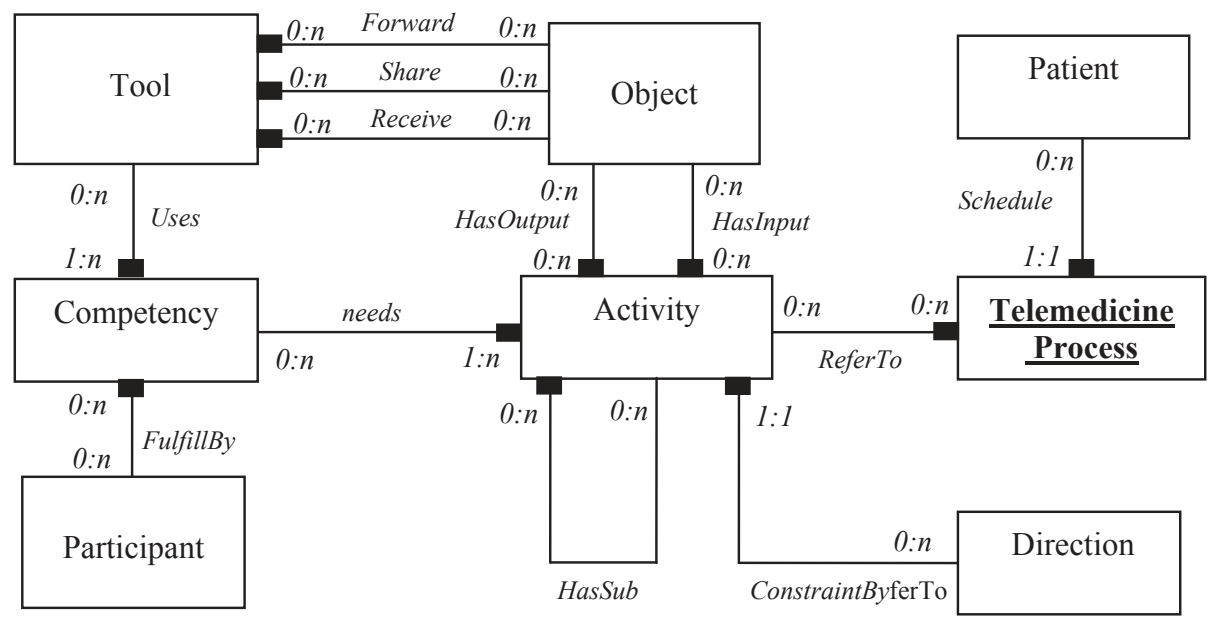

Fig. 3. The proposed telemedicine expert model. 


\subsection{Capitalization of knowledge from collaborative expertise}

In the Knowledge Acquisition (KA) community, there is the rise of situated cognition. There is growing insistence that much (perhaps all) of human decision making is critically dependent on the context in which it took place, suggesting that human problem solving could never be divorced from the myriad of environmental variables from every angle (Compton, 2012).

The research emphasis here highlights the concern about constructing coherent, robust models of problem solving. Intelligent systems will be modelled in terms of different kinds of primitives allowing us to conduct more advanced studies and to propose more comprehensive analysis (Musen, 2013):

(1) An ontology of the domain that captures the classes of entities that compose the application area (e.g., classes that describe medical treatment plans in general);

(2) A knowledge base in which the ontology is instantiated to provide the detailed content knowledge required by the system (e.g., the distinctions that define a particular medical treatment plan);

(3) A collection of domain-independent problem-solving methods that can automate the reasoning required to perform stereotypical tasks (e.g., a method such as skeletal-plan refinement, which can be used to plan medical treatment); and

(4) Mappings that relate the generic inputs and outputs of the problem-solving methods to referents in the domain ontology.

Problem Solving Methods (PSMs) could be re-used, and reuse of models or patterns is a sign of a mature and efficient engineering methodology. However, given the type of problem to be solved and domain knowledge characteristics, a suitable PSM could be selected. For instance, if the task is diagnosis, a PSM that tests and systematically eliminates suspect components following a system structure would be selected ('model based diagnosis). If the domain knowledge consists of classes of malfunctions (e.g., diseases), the major component of the PSM might consist of a (heuristic) classifier that connects symptoms with diseases (Breuker, 2013). The first model presented by Musen leaves out an important component regarding the use of the mapping to examine systemic telemedicine problems and to improve care. This requires the analysis of the structure of current (cognitive) work process and we need to go beyond summaries of models in order to provide analysis that contributes to the field of telemedicine. There are also now shared diagnostics, (e.g., by phone or other means), which the new system can potentially build upon. The expectation is that modeling shared diagnostics would run into many barriers, because among other factors, human cognition and diagnostics are very complex.

Tele-expertise involves knowledge models and reasoning mechanisms for distributed collaborative decision-making environments. These reasoning mechanisms are associated with the analysis of diagnosis and/or therapy, carried out in the absence of the patient. Meanwhile, tele-expertise will utilize feedback and capitalize on lessons derived from this work to consolidate and expand expertise in the field of operation.

Each complex situation for constructing advanced reasoning mechanisms, giving new opportunity to "lessons learned", can be used for future works that enrich the wealth of experience already established. All knowledge, findings of the work, and the completion of the demonstration are the main support of the valuation by capitalization of acquired expertise.

The management of the acquired knowledge is based on three interrelated components:

- Concrete traces stored as elements of knowledge representations are used in the application of expertise. Only traces stored on all media types, but often in information systems, lead to capitalization;

- Experts, the actors of expertise, are the main performers of traces during reuse of expertise; these actors also show that the analysis and solutions used as expressions of medical expertise are important because of the meanings they convey.

- The context associated with traces and the relevant expertise that gives the necessary understanding of the traces and the expression of their interpretation.

The capitalization of the traces can be facilitated and supported effectively by incorporating, for example, the following:

- Specification in a chronological table of all the activities, events, and decisions made during the test;

- The steps actually made using the expertise of the intelligence framework;

- The structure of expertise with its trees, and the various avenues actually explored;

- A directed graph over time of the basic knowledge obtained and assumptions (provided their attributes likelihood) chained to each other by ties of causal and / or logical succession;

- The balance of expertise or the expert conclusions that can be drawn from either organization specifically related to the case treated, or by validating for other cases of the same family;

- Acquired knowledge and know-how to master complex situations and obtain the desired outcomes.

The management of expertise can also be used if the organization is appropriate, the terms of technical meetings for sharing experiences are clarified, and the information systems (building databases with associated internal servers) have suitable user interfaces to ease access of capitalized information (reports, various documents, case files, etc.). 


\section{Discussion}

This section presents the lessons learned from this work from (a) requirement and processes modeling for collaboration point of views; and from (b) formalization and knowledge-based modeling for collaboration perspectives.

\subsection{Requirement and process nodeling for collaboration}

Telemedicine involves several activities such as (1) the consultation of patients, interpretation of necessary data collected, and follow-up by medical professional; (2) the inquire of opinions from geographically dispersed medical professionals who have the relevant training or skills; (3) the monitoring and remote supervision of patients; and (4) the assistance of a healthcare professional by a remote medical professional to assist remotely during the realization of a medical act.

Collaboration is highly needed among physicians or between physicians and other healthcare professionals involved in telemedicine protocols in accordance with the areas of different and complementary skills so that everyone is responsible for his/her actions and decisions.

Among other medical acts, telemedicine induces the same obligations for the physician, and patients benefit from the same rights as in a conventional medical practice. Non-compliance may engage professional oversight authorities.

Telemedicine applications require expert advice to develop a therapeutic decision, to prescribe treatment, recommend or perform services or other acts, or monitor a patient's condition. It allows organized networks to share information and skills, improve the management of patients, both for emergency care and chronic diseases (Kamsu-Foguem et al., 2015; KamsuFoguem et al., 2014a; Kamsu-Foguem et al., 2014b; Kamsu-Foguem et al., 2014c; Kamsu-Foguem and Foguem, 2014a; Kamsu-Foguem et al., 2013; Tafin-Kampé and Kamsu-Foguem, 2013; Kamsu-Foguem et al., 2012).

Telemedical intervention types include: measurement of vital signs using telemedical devices, interactive systems, or personal interaction between healthcare provider and patient. Telemedical final diagnosis on a remote patient is to be made only on the basis of a clinical evaluation or the result of further examination, while the prognosis of such patient with a serious disorder may be evident early on.

\subsection{Formalization and Knowledge-based Modeling for Collaboration}

In telemedicine, formalization of information exchanged between a requesting physician and medical expert is very important because it facilitates a transparent and traceable understanding of the telemedical process. This requires the definition of a suitable data exchange format adapted to the needs of performance assessment and secure information management. Therefore, confidentiality (Chopard et al., 2012) must be respected, and protection should be guaranteed by law through ethical principles and formal rules concerning the information to be shared, the procedures for sharing it, and the security of confidential information.

Depending on the nature of information to be shared in telemedicine, applications deployed may propose a synchronous or an asynchronous approach for implementing schemes of collaboration models. The practice of telemedicine must be exercised in respect of a number of principles to ensure the proper use of telemedicine, its added value in remote healthcare provisions and coordinated care pathways and ensure a reasoned practice and controlled engagement of advanced information and telecommunications technologies. This paper specifies and analyses some of the principles that stakeholders should have in mind throughout the deployment process of the telemedicine activities.

The use of telemedicine requires rigorous organization under the responsibility of doctors and computer scientists, based on clear rules and known to all, formalized by protocols written by the health authorities who will carry them out with the help of legal professionals, involved health structures (public or private health facilities) and biomedical device manufacturers (Doumbouya et al., 2015; Doumbouya et al., 2014; Kamsu-Foguem 2014a; Kamsu-Foguem 2014b; Kamsu-Foguem and Foguem, 2014b; Kamsu-Foguem and Foguem, 2014c).

Carried out in the absence of patients, telemedical expertises are associated with the analysis of diagnosis and/or therapy and are supported by knowledge models and reasoning mechanisms for distributed collaborative decision-making environments. Such expertises will utilize feedback and capitalize on lessons derived from this work to consolidate and expand expertise in the field of operation.

\section{Conclusion}

In this paper, we have shown that the engagement of knowledge-based modeling is interesting for supporting collaborative activities in telemedicine. In fact, the contribution of artificial intelligence techniques is tangible to provide hierarchical organization and perform information structuration and formalization. In telemedicine, the ontologies deliver semantic support to determine the most significant knowledge to assist in the establishment of the most appropriate diagnosis and to eliminate differential diagnoses. In particular, formal ontologies facilitate browsing and searching in an easily accessible fashion (e.g., semantic similarity of ontological entities queried by structural classes and by functional annotations). This promotes feedback on the experiences of users in employing the telemedicine framework and environment and represents a collaborative knowledge platform, which brings together project owners and solution providers with practitioners and professionals. 
There are also new research challenges and opportunities in the design and development of collaborative knowledge modeling, based, for example, on experience feedback processes or situations, and on the fundamental knowledgeable properties of such situations in order to manage their understanding, their control and the correct interpretation of the results for continuous improvement.

\section{References}

Adewale, Olumide Sunday, 2004. An internet-based telemedicine system in Nigeria. Int. J. Inf. Manage. 24 (3), $221-234$.

Breuker, Joost, 2013. A cognitive science perspective on knowledge acquisition 71 (2), 177-183.

Charpentier, G., Benhamou, P.Y., Dardari, D., Clergeot, A., Franc, S., Schaepelynck-Belicar, P., Catargi, B., Melki, V., Chaillous, L., Farret, A., Bosson, J.L., Penfornis, A.TeleDiab Study Group, 2011. The Diabeo software enabling individualized insulin dose adjustments combined with telemedicine support improves HbA1c in poorly controlled type 1 diabetic patients: a 6-month, randomized, open-label, parallel-group, multicenter trial (TeleDiab 1 Study). Diabetes Care 34 (3), 533-539. http://dx.doi.org/10.2337/dc10-1259 (Epub 2011 Jan 25).

Chopard, J.-L., Hubert, N., Moulin, T., Medeiros de Bustos, E., 2012. Legal, deontological and ethical issues applied to telemedicine. A few insights about telestroke. Eur. Rese.Telemed. (La Recherche Européenne en Télémédecine) 1 (2), 61-65.

Clark, R.A., Inglis, S.C., McAlister, F.A., Cleland, J.G., Stewart, S., 2007. Telemonitoring or structured telephone support programmes for patients with chronic heart failure: systematic review and meta-analysis. BMJ 334 (7600), 942 (Epub 2007 Apr 10).

Compton, P., 2012. Situated cognition and knowledge acquisition research. Int. J. Hum. Comput. Stud. 71 (2), 184-190.

DGOS, Technical Working Group/Information Systems, French Ministry of Employment, Labour and Health. Recommendations for the implementation of a telemedicine project, Technical Deployment: Urbanization and infrastructure, March 2012.

DOC (U.S. Department of Commerce), 1997. Telemedicine Report to Congress DOC Publication [On-line], U.S. Department of Commerce (DOC), Washington, DC. Available at: www.ntia.doc.gov.

Doering, Nora, Legido-Quigley, Helena, Glinos, Irene A., McKee, Martin, Maarse, Hans, 2013. A success-story in cross-border telemedicine in Europe: the use of intra-operative teleneuromonitoring during aorta surgery. Health Policy Technol. 2 (1), 4-9.

Doumbouya, M.B., Kamsu-Foguem, B., Kenfack, H., Foguem, C., 2014. Telemedicine using mobile telecommunication: towards syntactic interoperability in teleexpertise. Telemat. Inform. 31 (4), 648-659.

Doumbouya, M.B., Kamsu-Foguem, B., Kenfack, H., Foguem, C., 2015. A framework for decision making on teleexpertise with traceability of the reasoning. IRBM 36 (1), 40-51.

Ekeland, Anne G., Bowes, Alison, Flottorp, Signe, 2010. Effectiveness of telemedicine: a systematic review of reviews. Int. J. Med. Inform. 79 (11), $736-771$.

Franc, S., Daoudi, A., Mounier, S., Boucherie, B., Dardari, D., Laroye, H., Neraud, B., Requeda, E., Canipel, L., Charpentier, G., 2011. Telemedicine and diabetes: achievements and prospects. Diabetes Metab. 37 (6), 463-476.

Kamsu-Foguem, B., 2014a. Systemic modeling in telemedicine, Eur. Res. Telemed. 3 (2), 57-65.

Kamsu-Foguem, B., 2014b. Ontological view in telemedicine. Eur. Res. Telemed. 3 (2), 67-76.

Kamsu-Foguem, B., Diallo, G., Foguem, C., 2013. Conceptual graph-based knowledge representation for supporting reasoning in African traditional medicine. Eng. Appl. Artif. Intell. 26 (4), 1348-1365.

Kamsu-Foguem, B., Foguem, C., 2014a. Adverse drug reactions in some African herbal medicine: literature review and stakeholders' interview. Integr. Med. Res. 3 (3), 126-132.

Kamsu-Foguem, B., Foguem, C., 2014b. Could telemedicine enhance traditional medicine practices? Eur. Res. Telemed. 3 (3), $117-123$.

Kamsu-Foguem, B., Foguem, C., 2014c. Telemedicine and mobile health with integrative medicine in developing countries. Health Policy Technol. 3 (4), 264271.

Kamsu-Foguem, B., Tchuenté-Foguem, G., Foguem, C., 2014a. Using conceptual graphs for clinical guidelines representation and knowledge visualization. Inform. Syst. Front. 16 (4), 571-589.

Kamsu-Foguem, B., Tchuenté-Foguem, G., Allart, L., Zennir, Y., Vilhelm, C., Mehdaoui, H., Zitouni, D., Hubert, H., Lemdani, M., Ravaux, P., 2012. User-centered visual analysis using a hybrid reasoning architecture for intensive care units. Decis. Support Syst. 54 (1), 496-509.

Kamsu-Foguem, B., Tchuenté-Foguem, G., Foguem, C., 2014b. Conceptual graph operations for formal visual reasoning in the medical domain. IRBM 35 (5), $262-270$.

Kamsu-Foguem, B., Tchuenté-Foguem, G., Foguem, C., 2014c. Verifying a medical protocol with temporal graphs: The case of a nosocomial disease. J. Crit. Care 29 (4), 690.e1-690.e9.

Kamsu-Foguem, B., Tiako, P.F., Mutafungwa, E., Foguem, C., 2015. Knowledge-based modelling applied to synucleinopathies. Eur. Geriatr. Med. http:// dx.doi.org/10.1016/j.eurger.2015.02.011.

Musen, Mark A., 2013. The knowledge acquisition workshops: a remarkable convergence of ideas. Int. J. Hum. Comput. Stud. 71 (2), $195-199$.

Pattynama, Peter M.T., 2010. Legal aspects of cross-border teleradiology. Eur. J Radiol. 73 (1), 26-30.

Polisena, J., Tran, K., Cimon, K., Hutton, B., McGill, S., Palmer, K., Scott, R.E., 2010. Home telemonitoring for congestive heart failure: a systematic review and meta-analysis. J. Telemed. Telecare 16 (2), 68-76. http://dx.doi.org/10.1258/jtt.2009.090406 (Epub 2009 Dec 11).

Saliba, Vanessa, Legido-Quigley, Helena, Hallik, Riina, Aaviksoo, Ain, Car, Josip, McKee, Martin, 2012. Telemedicine across borders: a systematic review of factors that hinder or support implementation. Int. J. Med. Inform. 81 (12), 793-809.

Siegal, Gil, 2011. Telemedicine: licensing and other legal issues. Otolaryngol. Clin. North Am. 44 (6), 1375-1384.

Simon, P., Pellitteri, Williatte, 2012. Le décret français de télémédecine: une garantie pour les médecins. Eur. Res. Telemed. 1 (2), $70-75$.

Stamm, B.H., Friedman, M.J, Schnurr, P., Hsieh, F., Rudolph, J.M, and Millman, A., 1998. Using telemedicine tools for the administration of a multi-site clinical trial. In: Poster to be presented at the Annual meeting of the American Telemedicine Association, Orlando, FL. [http://www.dartmouth.edu/ csp420/ professional/csp420ata.pdf].

Tafin-Kampé, K., Kamsu-Foguem, B., 2013. Acute osteomyelitis due to Staphylococcus aureus in children: What is the status of treatment today? Pediatr. Infect. Dis. 5 (3), 122-126.

Telemd Health HDHP, 1stGMC, Global Media \& Communication, A Telemedical Remote Office Facility Routed Through a Virtual Private Network, technical document, [http://www.tele-medical-health-hipaa-dicom-hl7-pacs.com/telemedical-telehealth-hipaa-dicom-hL7-pacs-network.html] (last accessed 14 October 2013).

Tiako, P.F., 2011a. Process modeling, delegation and control in global software development. Int. J. Comput. Appl. Technol. 40 (30).

Tiako, P.F., 2011b. Perspectives of delegation in team-based distributed software development over the GENI infrastructure. In: Proceedings of the 33rd International Conference on Software Engineering, ICSE 2011, May 21-28, 2011, Waikiki Honolulu, HI, USA. ACM.

van den Berg, Neeltje, Schumann, Maika, Kraft, Kathleen, Hoffmann, Wolfgang, 2012. Telemedicine and telecare for older patients-a systematic review. Maturitas 73 (2), 94-114

Bernard Kamsu Foguem: He is currently a tenured Associate Professor at the National Engineering School of Tarbes (ENIT) of National Polytechnic Institute of Toulouse (INPT) and undertakes research in the Production Engineering Laboratory (LGP) of ENIT-INPT, a research entity (EA1905) of the University of Toulouse. He is a visiting scholar in some renowned universities: United Kingdom (e.g. Oxford Brookes University, Oxford), Finland (e.g. Aalto University, Helsinki University of Technology, VTT Technical Research Centre of Tampere, University of Oulu, Åboakademi of Turku University). He is also involved in the thematic group: e-Health of InterOP-VLab (International Virtual Laboratory for Enterprise Interoperability). He is a member of International Editorial 
Reviewer Board of Artificial Intelligence Research and a reviewer for a large number of international scientific journals such as Knowledge-Based Systems, Engineering Applications of Artificial Intelligence, International Journal of Production Research, Journal of Intelligent Manufacturing, Computer Methods and Programs in Biomedicine, Computers in Biology and Medicine, Interacting with Computers, Sensors and Knowledge Management Research \& Practice. He got the "accreditation to supervise research", abbreviated HDR from University of Toulouse in 2013. He has a Master's in Operational Research, Combinatorics and Optimization (2000) from National Polytechnic Institute of Grenoble, and a PhD in Computer Science and Automation (2004) from the University of Montpellier 2. His current interests are in Knowledge Discovery and Data Mining, Knowledge Representation, Formal Visual Reasoning, Ontology-based Semantic Analysis, Knowledge Exploitation for remote Collaboration, Decision Support Systems and Intelligent Systems. The application range is extensive and includes Continuous Improvement Processes, Reliability centered Maintenance, Building Information Modeling and Health Information Systems.

Pierre Fernand Tiako: He is the Director of the Center for Information Technology Research at Langston University (USA) and a Professor of Computer Science and Information System. He is the Promoter of Tiako University with a small campus coming soon in downtown Oklahoma City. He worked as a Visiting Professor at Oklahoma State University (OSU) before the current positions. Prior to OSU, he taught computer science courses and did research at Universities of Lorraine and Rennes (France), and also worked as an expert engineer at INRIA, the French national institute for research in information technology. Dr. Tiako has authored more than 60 journal and conference technical papers and co-edited four proceedings volumes, resulting from services as program chair for several international conferences and workshops. He holds a PhD in Software and Information Systems Engineering from University (National Polytechnic Institute) of Lorraine (France). Dr. Tiako is a senior member of IEEE and past Chairman for IEEE Oklahoma City Section.

Laure Pauline Fotso: Professor Laure P. Fotso is the Coordinator of UNU-INRA's operating unit in Cameroon. From the 1977 academic year onwards, Prof Fotso held the position of Consulting Programmer at State University of New York at Albany (SUNYA), and a Teaching and Research Assistant at Rensselaer Polytechnic Institute (RPI). Back home in 1981, Prof Fotso taught courses in computer sciences at the Faculty of Science, University of Yaoundé I. From October 2004 to January 2009, she was the Vice-Dean at the Faculty of Science of the University of Yaoundé I. Since January 2009, she has held the position of Vice-Rector in charge of Internal Control and Evaluation at the University of Dschang, Cameroon. Prof Fotso has co-directed two PhD theses and directed more than thirty master's degree theses. She has authored three books and several scientific papers in peer review journals and communications.

Clovis Foguem: He is an Internal Medicine and Geriatric medical doctor and has undertaken a PhD on 'Olfaction and Elderly: study of the olfactory (CN I) and trigeminal (CN V) sensitivities interactions in a geriatric population; constants and pathological specificities'. He is also particularly interested in neurodegenerative diseases (as Parkinson disease or Lewy Body dementia), elderly epilepsy and whether pathogenic inflammatory or autoimmune responses can contribute to these disorders in the elderly. Moreover he is also interested in medical knowledge representation and medical clinic design guidelines. For his work on 'Olfaction and Elderly', Dr C. Foguem was laureate of Health Research Award for emerging health researchers from the corporate foundation 'Groupe Pasteur Mutualité' in 2011. He is grounded in medical research applications of Information and Communications Technology. Former Faculty of Medicine's Clinical Instructor, he is now Hospital Practitioner in France. He is peer-reviewer of many scientist journals among which: Clinical Interventions in Aging; Degenerative Neurological and Neuromuscular Disease; International Medical Case Reports Journal; Neuroscience and Neuroeconomics; Clinical Medicine Insights; Journal of the Pancreas; International Scholars Journals (ISJ); Cancer Therapy; Indian Journal of Critical Care Medicine and, African Journal of Environmental Science and Technology. 